\title{
Periodic Mounts to Isolate the Vibrations of Automotive Vehicle Engine
}

\author{
Saeed Asiri and A.A.N. Aljawi \\ Mechanical Engineering, Faculty of Engineering, King Abdulaziz University \\ Jeddah, Saudi Arabia \\ saeed@asiri.net and azharinn@yahoo.com
}

\begin{abstract}
In this paper, a new class of periodic mounts for isolating the vibration transmission from vehicle engine to the car body and seats is presented. Periodic mounts exhibit unique dynamic characteristics that make them act as mechanical filters for wave propagation. As a result, waves can propagate along the periodic mounts only within specific frequency bands called the "Pass Bands" and wave propagation is completely blocked within other frequency bands called the "Stop Bands".

The experimental arrangements, including the design of mounting systems with plain and periodic mounts are studied first. The dynamic characteristics of such systems will be obtained experimentally in both cases. Tests are then carried out to study the performance characteristics of periodic mounts with geometrical and/or material periodicity. The effectiveness of the periodicity on the vibration levels of mounting systems has been demonstrated theoretically and experimentally. Finally, the experimental results are compared with the theoretical predictions. Good agreement is obtained between theory and experiments.
\end{abstract}

Keywords: Transfer matrix, vibration isolation, periodic mounts.

\section{Introduction}

Customer awareness and sensitivity to noise and vibration levels caused the transportation industry to regard noise and vibration as important criteria for improving market shares. One important source of mechanical vibration in automobiles is the engine. The vibrations of the engines may 
cause structural failure, malfunction of other parts, or discomfort to passengers because of high level noise and vibrations. The mounts of the engines act as the transmission paths of the vibrations transmitted from the excitation sources to the body of the vehicle and passengers. Therefore, proper design and control of these mounts are essential to the attenuation of the vibration of platform structures. To improve vibration resistant capacities of engine mounting systems, vibration control techniques may be used. For instance, some passive and semi-active dissipation devices may be installed at mounts to enhance vibration energy absorbing capacity. Analysis and design of such mounts are the main objectives of this paper.

In general, vibration isolation can be achieved partially with the use of many types of compliant connections between the vibration source and the device to be protected. The classical approach to design isolation systems focuses primarily on the properties of those compliant plain mounts without regard to the effect of using the periodicity concept on the isolated device.

The study of periodic structures has a long history. Wave propagation in periodic systems related to crystals, optics, and the like has been investigated for approximately 300 years. Brillouin [1] developed the theory of periodic structures for solid state applications and then, in the early seventies, the theory was extended to the design of mechanical structures ${ }^{[2,3]}$. Since then, the theory has been extensively applied to a wide variety of structures such as spring-mass systems ${ }^{[4]}$, periodic beams ${ }^{[2,5-8]}$ stiffened plates ${ }^{[7-8]}$, ribbed shells ${ }^{[7]}$ and space structures. Examples of such structures are found in many engineering applications. These include bulkheads, helicopter drive shaft ${ }^{[9]}$, airplane fuselages, vehicle engine mounting systems ${ }^{[10]}$, and helicopter gearbox supporting system [11]. Each such structure has a repeating set of stiffeners which are placed at regular intervals. Sackman et al. ${ }^{[12]}$ presented a layered notch filter device in passive mode that is limited only for high-frequency vibrations. Such Filter which was developed theoretically based on Floquet theory is a periodically layered stack of alternating materials with widely different densities and stiffnesses. Using modal analysis Szefi ${ }^{[13]}$ examined the effects of three-dimensional elasticity on periodically layered isolators in compression. 
Periodic rods in their passive mode of operation exhibit unique dynamic characteristics that make them act as mechanical filters for wave propagation. As a result, waves can propagate along the periodic rods only within specific frequency bands called the "Pass Bands" and wave propagation is completely blocked within other frequency bands called the "Stop Bands". The spectral width and location of these bands are fixed for 1-D passive periodic structure, but tunable in response to the structural vibration for active periodic structures ${ }^{[14,15]}$. Asiri et al. ${ }^{[15]}$ presented a tunable mechanical filter with active periodic rods in a quasistatic manner, to isolate the wave propagation of longitudinal vibration. To model the tunable mechanical filter, the spectral finite element analysis and transfer matrix method ${ }^{[14]}$ will be used to analyze the hybrid periodic rod and determine the propagation parameter, $\mu$ which indicates the regions of stop bands and pass bands.

This paper is organized in four sections. In Section 1, a brief introduction is given. Section 2 presents the theoretical background of passive mounts and Section 3 demonstrates the performance characteristics of the mounts alone as well as the mounts and engine system assembly. Comparisons between the theoretical and experimental characteristics are also presented in Section 3. Section 4 summarizes the findings and the conclusions of the present study as well as the direction for future research.

\section{Theoretical Modeling of Periodic Mounts}

\subsection{Overview}

In this section, the emphasis is placed on studying the dynamics of one-dimensional periodic mounts in their passive mode of operation. The dynamics of one-dimensional periodic mounts are determined using the transfer matrix method. The basic characteristics of the transfer matrices of periodic mounts are presented and related to the physics of wave propagation along these mounts. The methodologies for determining the pass and stop bands as well as the propagation parameters are presented. 


\subsection{Dynamics of Passive Mounts}

\subsubsection{General}

Consider the generic one-dimensional periodic mount shown in Fig. 1. The undamped dynamics of the $k^{\text {th }}$ cell are determined from the following finite element expression:

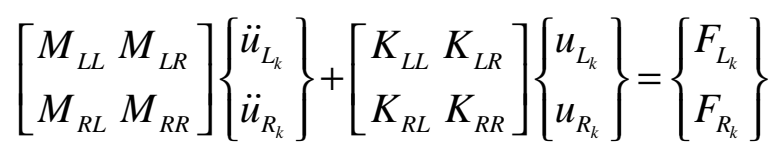

where $M_{i j}$ and $K_{i j}$ are appropriately partitioned matrices of the mass and stiffness matrices. Also, $u$ and $F$ define the deflection and force vectors with subscripts $L_{i}$ and $R_{i}$ denoting the left and right sides of the $k_{t h}$ cell.

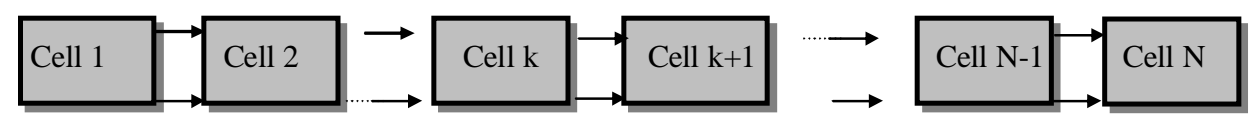

(a) Periodic mount with $\mathrm{N}$ cells
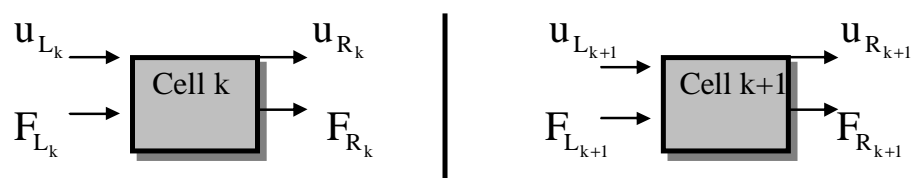

Interface I

(b) - Interaction between two consecutive cells

Fig. 1. One-dimensional periodic mount.

For a sinusoidal excitation at a frequency $\omega$, Equation (1) reduces to:

$$
\begin{aligned}
& {\left[\begin{array}{cc}
K_{L L}-M_{L L} \omega^{2} & K_{L R}-M_{L R} \omega^{2} \\
K_{R L}-M_{R L} \omega^{2} & K_{R R}-M_{R R} \omega^{2}
\end{array}\right]\left\{\begin{array}{c}
u_{L_{k}} \\
u_{R_{k}}
\end{array}\right\}=\left\{\begin{array}{c}
F_{L_{k}} \\
F_{R_{k}}
\end{array}\right\}, \text { or }} \\
& {\left[\begin{array}{ll}
K_{d_{L L}} & K_{d_{L R}} \\
K_{d_{R L}} & K_{d_{R R}}
\end{array}\right]\left\{\begin{array}{l}
u_{L_{k}} \\
u_{R_{k}}
\end{array}\right\}=\left\{\begin{array}{l}
F_{L_{k}} \\
F_{R_{k}}
\end{array}\right\} .}
\end{aligned}
$$

where: $\mathrm{Kd}$ is the dynamic stiffness matrix of the $k_{t h}$ cell. 
Equation (2) is rearranged to take the following form:

$$
\left\{\begin{array}{c}
u_{R_{k}} \\
F_{R_{k}}
\end{array}\right\}=\left[\begin{array}{cc}
-K_{d_{L R}}^{-1} K_{d_{L L}} & K_{d_{L R}}^{-1} \\
-K_{d_{R R}} K_{d_{L R}}^{-1} K_{d_{L L}}+K_{d_{R L}} & K_{d_{R R}} K_{d_{L R}}^{-1}
\end{array}\right]\left\{\begin{array}{l}
u_{L_{k}} \\
F_{L_{k}}
\end{array}\right\}
$$

Considering now the compatibility and equilibrium conditions at the interface between the $\mathrm{kth}$ and the $\mathrm{k}+1$ th cells, yields the following expressions:

$$
u_{R_{k}}=u_{L_{k+1}} \text { and } F_{R_{k}}=-F_{L_{k+1}}
$$

Substituting these conditions into Equation (3), it reduces to:

$$
\left\{\begin{array}{l}
u_{L_{k+1}} \\
F_{L_{k+1}}
\end{array}\right\}=\left[\begin{array}{cc}
-K_{d_{L R}}^{-1} K_{d_{L L}} & K_{d_{L R}}^{-1} \\
K_{d_{R R}} K_{d_{L R}}^{-1} K_{d_{L L}}-K_{d_{R L}} & -K_{d_{R R}} K_{d_{L R}}^{-1}
\end{array}\right]\left\{\begin{array}{c}
u_{L_{k}} \\
F_{L_{k}}
\end{array}\right\}
$$

In a more compact form, Equation (5) can be rewritten as:

$$
\left\{\begin{array}{l}
u_{L} \\
F_{L}
\end{array}\right\}_{k+1}=\left[\begin{array}{l}
t_{11} t_{12} \\
t_{21} t_{22}
\end{array}\right]\left\{\begin{array}{l}
u_{L} \\
F_{L}
\end{array}\right\}_{k} \text { or } \quad Y_{k+1}=\left[T_{k}\right] Y_{k}
$$

where $Y$ and $\left[T_{k}\right]$ denote the state vector $=\left\{u_{L} F_{L}\right\}^{T}$ and the transfer matrix of the $k_{t h}$ cell. Note that the transfer matrix relates the state vector at the left end of $k+l_{t h}$ cell to that at the left end of the kth cell. For exactly periodic mounts, $\left[T_{k}\right]=[T]$ and the eigenvalue problem of $[T]$ can be written as:

$$
[T] Y_{k}=\lambda Y_{k}
$$

Combining Equation (6) and (7) gives:

$$
Y_{k+1}=\lambda Y_{k}
$$

indicating that the eigenvalue $\lambda$ of the matrix $[T]$ is the ratio between the state vectors at two consecutive cells. 
Hence, one can reach the following conclusions:

a) If $|\lambda|=1$, then $Y_{k+1}=Y_{k}$ and the state vector propagates along the mount as it is. This condition defines a "Pass Band" condition, and

b) If $|\lambda|<1$, then $Y_{k+1}<Y_{k}$ and the state vector is attenuated as it propagates along the mount. This condition defines a "Stop Band" condition.

A further explanation of the physical meaning of the eigenvalue $\lambda$ can be extracted by rewriting it as:

$$
\lambda=e^{\mu}=e^{\alpha+i \beta}
$$

where $\mu$ is defined as the "Propagation Constant" which is a complex number whose real part $(\alpha)$ represents the logarithmic decay of the state vector and its imaginary part $(\beta)$ defines the phase difference between the adjacent cells.

\subsubsection{Uniform mounts}

Consider the plain rod of Fig. (2) :

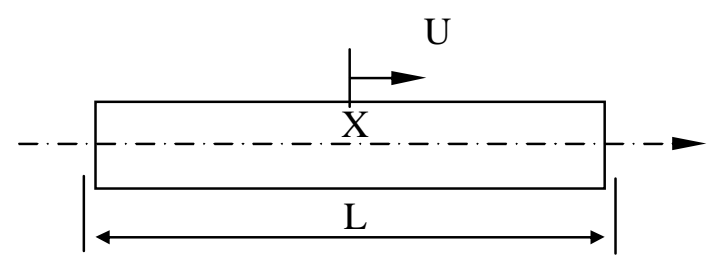

Fig. 2. Mount undergoing longitudinal vibrations.

As the Equation of motion of the rod is given by:

$$
u_{x x}-(\rho / E) u_{t t}=0
$$

where $\mathrm{u}$ is the longitudinal deflection, $\rho$ is the density and $\mathrm{E}$ is Young's modulus. 
Then, assuming a solution $u(x, t)=U(x) e^{i \omega t}$, reduces the Equation of motion to:

$$
\begin{aligned}
U_{x x}(x)+(\rho / E) \omega^{2} U(x) & =0, \\
U_{x x}(x)+k^{2} U(x) & =0
\end{aligned}
$$

where: $\mathrm{k}=$ wave number $=\sqrt{\rho / \mathrm{E}} \omega$.

Using the following spectral shape function: $U(x)=A e^{-i k x}+B e^{i k x}$, which is also a solution of Equation (10), yields the spectral finite element description of the dynamics of the mount as outlined by Doyle $^{[16]}$. This results in the following dynamic stiffness matrix of the mount:

$$
[K]=\frac{E A}{L}\left[\begin{array}{cc}
\left(1-e^{-4 i k L}\right) i k L & -2 e^{-3 i k L}\left(-1+e^{2 i k L}\right) i k L \\
-2 e^{-3 i k L}\left(-1+e^{2 i k L}\right) i k L & \left(1-e^{-4 i k L}\right) i k L
\end{array}\right]
$$

The corresponding Transfer Matrix [T] takes the following form:

$$
\begin{aligned}
& {[T]=\left[\begin{array}{lc}
-K_{d_{L R}}^{-1} K_{d_{L L}} & K_{d_{L R}}^{-1} \\
K_{d_{R R}} K_{d_{L R}}^{-1} K_{d_{L L}}-K_{d_{R L}} & -K_{d_{R R}} K_{d_{L R}}^{-1}
\end{array}\right]} \\
& \text { where } K_{d_{L L}}=\frac{E A}{L}\left(1-e^{-4 i k L}\right) i k L, \\
& K_{d_{L R}}=\frac{E A}{L}\left(-2 e^{-3 i k L}\left(-1+e^{2 i k L}\right) i k L\right), \\
& K_{d_{R L}}=\frac{E A}{L}\left(-2 e^{-3 i k L}\left(-1+e^{2 i k L}\right) i k L\right), \text { and } \\
& K_{d_{R R}}=\frac{E A}{L}\left(1-e^{-4 i k L}\right) i k L
\end{aligned}
$$




\subsubsection{Periodic mounts}

Consider now the longitudinal vibrations of the periodic mounts with geometrical or material discontinuities as shown in Fig. (3).

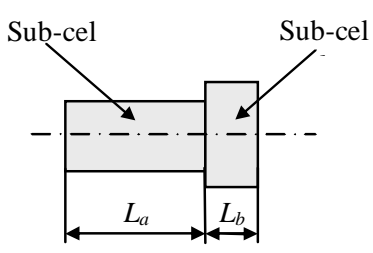

(a) Geometrical periodicity

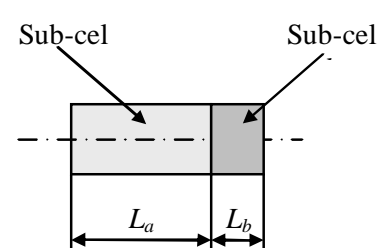

(b) Material periodicity

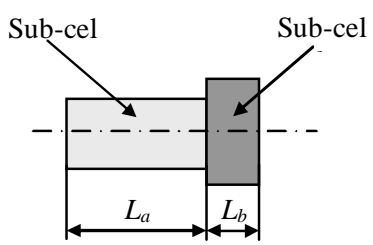

(c) Geometrical and material periodicity

Fig. 3. The periodicity types of a unit cell of passive periodic mounts.

The dynamics characteristics of the individual substructure ( $a$ or $b$ ) can be described by its transfer matrix $\left[T_{s}\right]$, as defined by Equation (12), as follows:

$$
\left[T_{s}\right]=\left[\begin{array}{cc}
\frac{\left(1+e^{-2 i k_{s} L_{s}}\right)}{2 e^{-i k_{s} L_{s}}} & -\frac{L_{s}}{E_{s} A_{s}} \frac{\left(1-e^{-2 i k_{s} L_{s}}\right)}{2 i k_{s} L_{s} e^{-i k_{s} L_{s}}} \\
-\frac{E_{s} A_{s}}{L_{s}} \frac{i k_{s} L_{s}\left(1-e^{-2 i k_{s} L_{s}}\right)}{2 e^{-i k_{s} L_{s}}} & \frac{\left(1+e^{-2 i k_{s} L_{s}}\right)}{2 e^{-i k_{s} L_{s}}}
\end{array}\right] \text { with } s=a, b
$$

Combining the transfer matrices of the substructures a and $b$, yields the transfer matrix $[T]$ for the asymmetric unit cell as follows:

$$
[T]=\left[T_{b}\right][T a]
$$


The eigenvalues of the transfer matrix $[T]$ of the unit cell can then be calculated to determine the propagation parameter and the stop/pass bands of mounts with various geometrical and material discontinuities.

\section{Performance of the Passive Mounts}

\subsection{Overview}

In order to demonstrate the feasibility of the concepts presented in Section 2, experimental investigations were conducted. These investigations were carried out in two stages. In the first stage, the vibration attenuation characteristics of several configurations of the passive mount were determined and evaluated. These configurations were then integrated with an engine assembly to evaluate their performance as means for attenuating the vibration transmission from the engine to the body.

\subsection{Experimental Facilities}

In this study, two experimental test rigs have been employed to evaluate the performance of the passive periodic mounts. The first test rig aimed at monitoring the vibration transmission characteristics of the mounts alone as influenced by geometrical and material discontinuities. Figure 4 shows the details of the employed test facility.

The second experimental setup shown in Fig. 5 was used to measure the vibration transmission from the engine to the body through a set of four passive periodic mounts. The setup is used specifically to study the effect of the geometrical and material discontinuities on the vibration transmitted through these mounts.

In this experiment, the struts were cut in three forms, plain struts as show in Fig. 6(a), geometrical struts shown in Fig. 6(b) and material and geometrical discontinuity struts as shown in Fig. 6(c) which consist of Aluminum and Rubber with the diameters and lengths shown in Table 1 with different number of cells starting from two cells to five cells to compare between them and to show the effectiveness of the number of cells on the vibration isolation process. In Material and Geometrical Discontinuity Struts, the Aluminum and Rubber were fixed together using a special kind of glue which can carry the applied loads. 


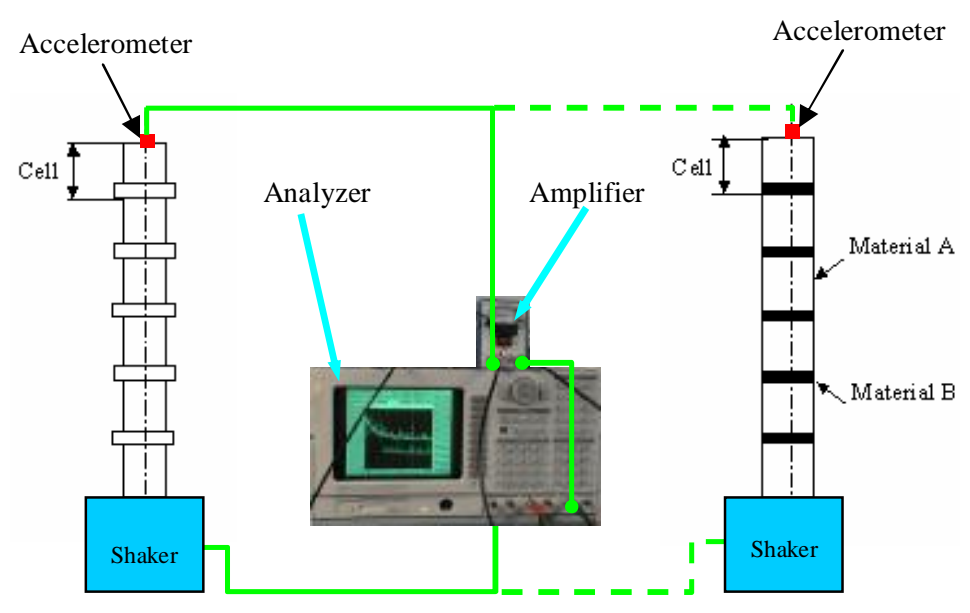

(a) Mount with geometrical discontinuity

(b) Mount with material discontinuity

Fig. 4. Experimental setup for evaluating the vibration transmission characteristics of the mounts.

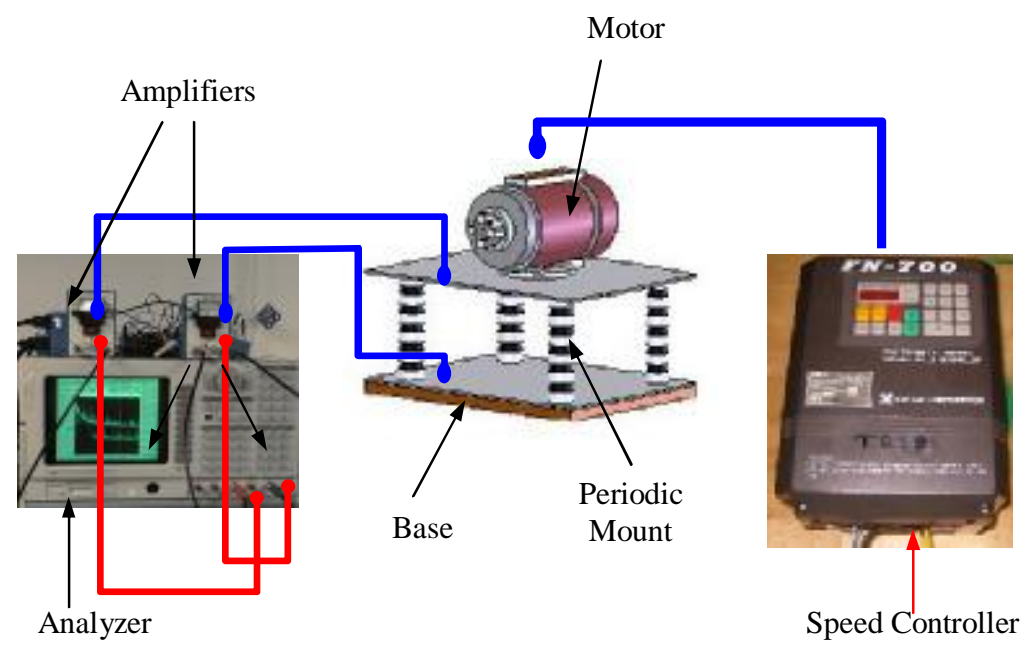

Fig. 5. Experimental setup for measuring vibration transmission with periodic mounts. 


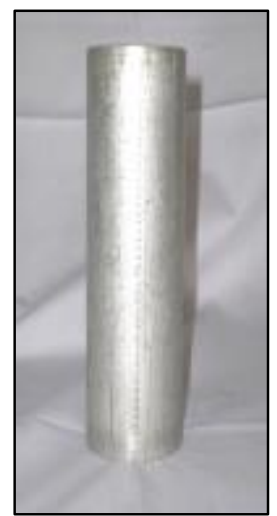

(a)

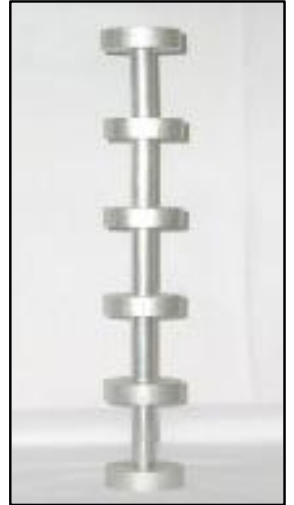

(b)

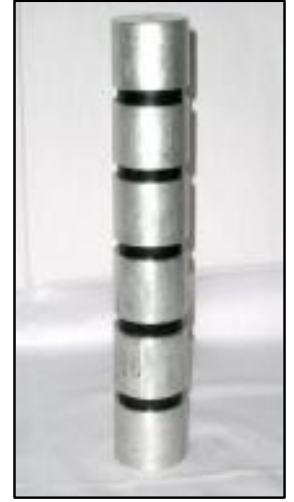

(c)

Fig. 6. Types of struts used during the experimental setup, (a) Plain Strut, (b) Geometrical Strut, (c) Material and Geometrical Discontinuity Strut.

Table 1. The diameters and lengths of Aluminum and Rubber cells.

\begin{tabular}{|c|c|c|}
\hline & Diameter, mm & Length, mm \\
\hline Aluminum & 50 & 20 \\
\hline Rubber & 43 & 15 \\
\hline
\end{tabular}

\subsection{Finite Element Modeling}

In the present study, ANSYS FE code is employed to investigate the dynamic characteristics of the mounts. The specifications of the model shown in Fig. 7 are as follows:

- Element type used is Solid Brick eight Node 92 for rigid bodies.

- Material properties: the material properties used in the models is shown in Table 2.

- Degrees of freedom: all models were constrained at X-Y directions. So one degree of freedom was applied which is translation in Z-direction.

- Mesh type is smart size 6-default.

- Solution: Modal Analysis and Harmonic Response Analysis. 


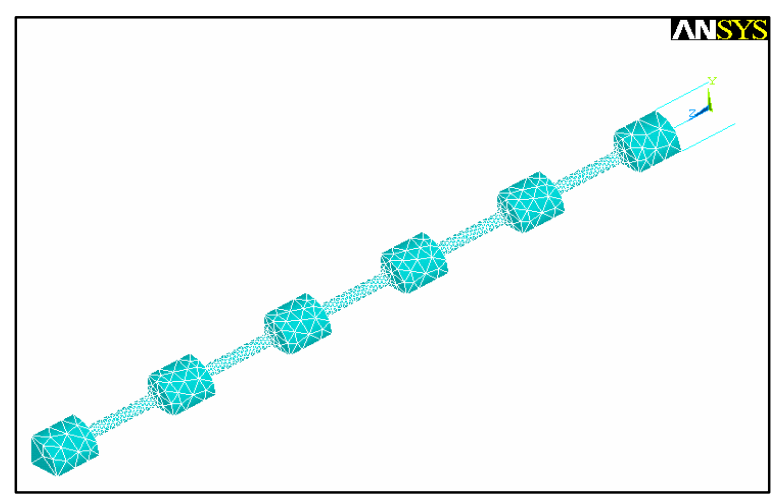

Fig. 7. ANSYS FE model for material and geometrical discontinuity strut of five cells.

Table 2. Material properties.

\begin{tabular}{|c|c|c|}
\hline Material & Density $\left(\mathrm{kg} / \mathrm{m}^{3)}\right.$ & Modulus of Elasticity (GPa) \\
\hline Aluminum & 2700 & 69 \\
\hline Steel & 7000 & 207 \\
\hline $\begin{array}{c}\text { Rubber (Mearthane } \\
\text { Durethane) }\end{array}$ & 1200 & 0.00245 \\
\hline
\end{tabular}

\section{Discussion of Results}

\subsection{Mount Alone}

\subsubsection{Periodic Mounts with Geometrical Discontinuity}

Figures 8(a) and 8(b) show respectively the magnitude of the experimental and numerical transfer function (TR) between the input excitation as applied to one end of the mount and the transmitted acceleration to the other end of the mount as obtained by a passive mount with geometrical discontinuities. Good agreement can be observed between the experimental and numerical results using ANYSYS FE model. The displayed results indicate clearly attenuation of the vibration for the start of the frequencies higher than $12,000 \mathrm{~Hz}$. Figure $8 \mathrm{c}$ shows that the stop band can be clearly predicted theoretically by plotting the real part $\alpha$ of the propagation parameter $\mu$. For values of $\alpha \neq 0$, the stop band can be clearly identified and match closely the experimental and numerical (ANSYS) results. Figures $9 \& 10$ show other configurations of periodic mounts with geometrical periodicities, which clarifiy the effect of geometrical parameters on the location of the stop band. 


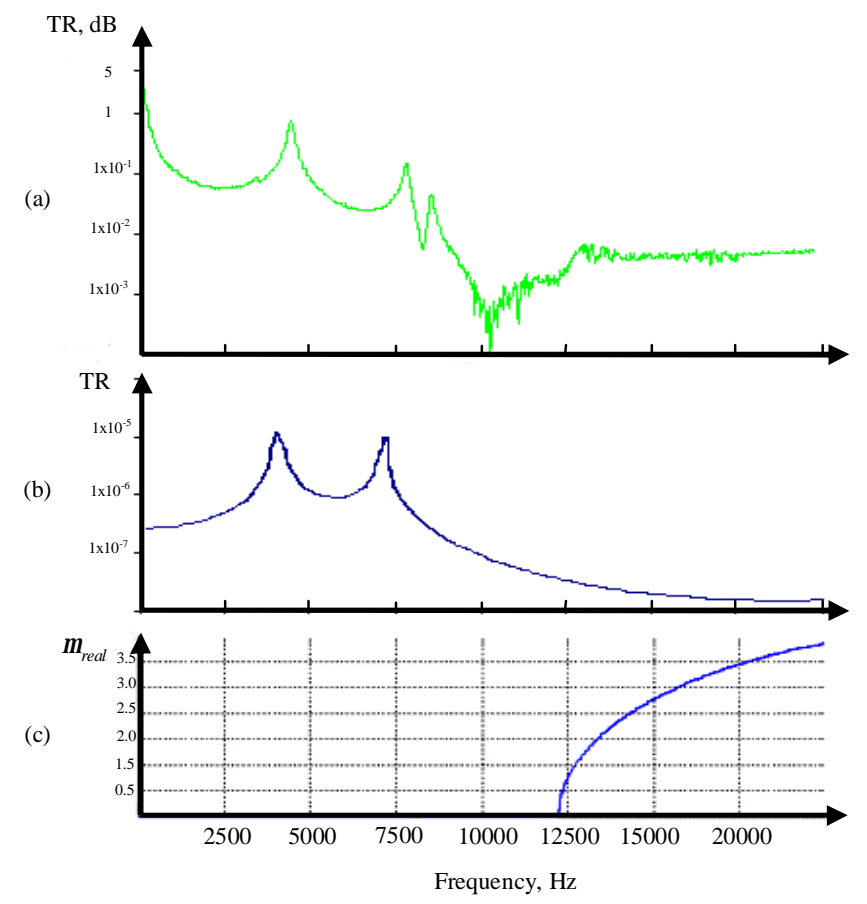

Fig. 8. Experimental and numerical TF using ANSYS, and propagation parameter for a periodic mount with geometrical discontinuities $\left(D_{a}=15 \mathrm{~mm}, L_{a}=70 \mathrm{~mm}, D_{b}=50\right.$ $m m$, and $L_{b}=20 \mathrm{~mm}$ ).

(a)

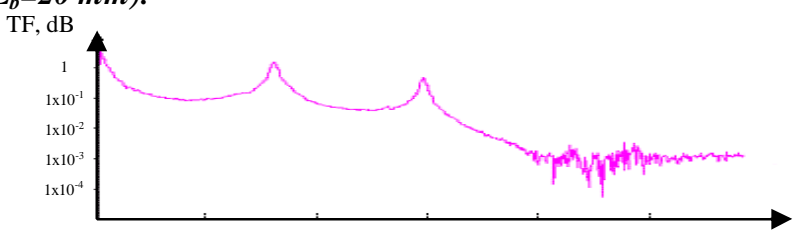

(b)

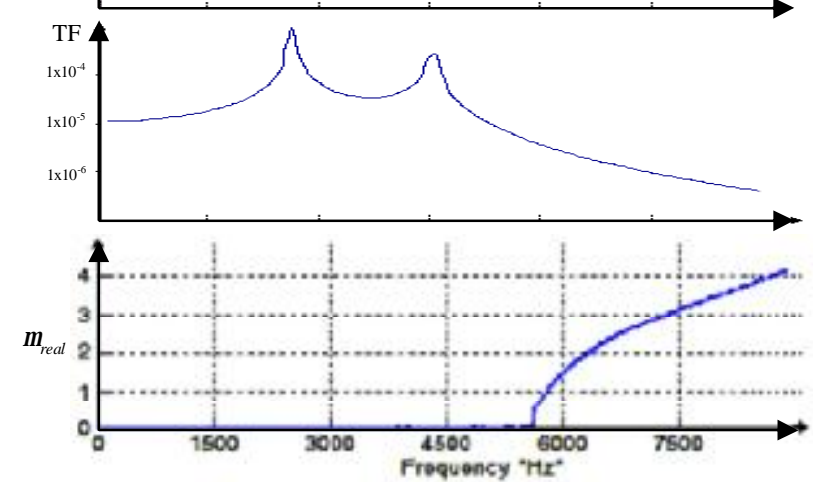

Fig. 9. Experimental and numerical TF using ANSYS, and propagation parameter for a periodic mount with geometrical discontinuities $\left(D_{a}=5 \mathrm{~mm}, L_{a}=50 \mathrm{~mm}, D_{b}=50\right.$ $m m$, and $L_{b}=24 \mathrm{~mm}$ ). 


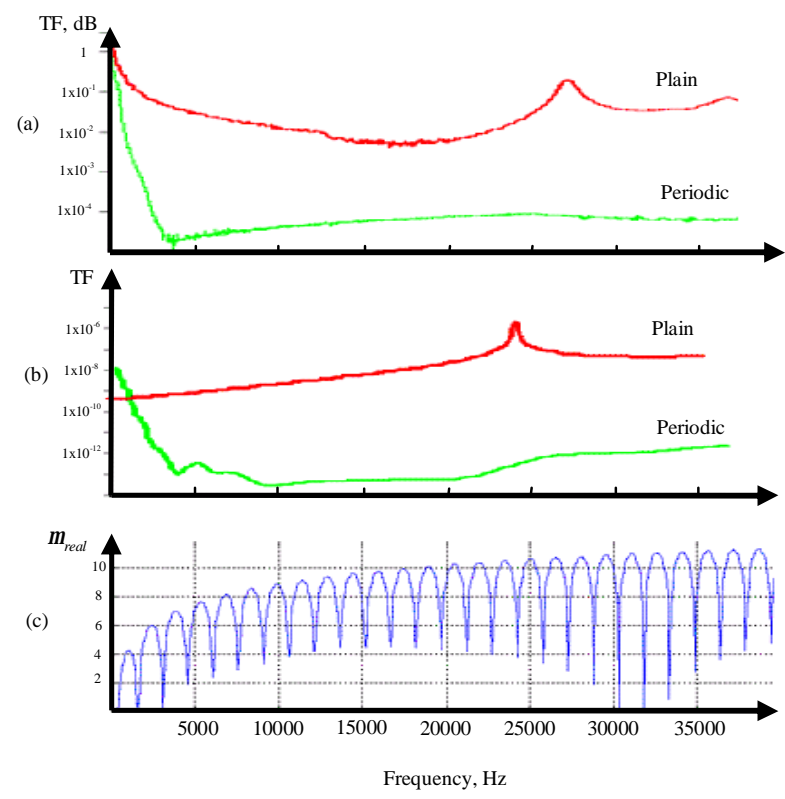

Fig. 10. Experimental and numerical TF using ANSYS, and real part of propagation factor for a periodic mount with geometrical and material discontinuities ( $D_{a}=50 \mathrm{~mm}$, $L_{a}=20 \mathrm{~mm}, D_{b}($ Rubber $)=43 \mathrm{~mm}$, and $\left.L_{b}=15 \mathrm{~mm}\right)$.

\subsubsection{The Periodic Mounts on the Shaker}

Figure 11 shows clearly that the periodic mounts are much more effective than the engine seats in attenuating the transmission of vibration from the shaker to the upper plate through the periodic mounting system.

\subsubsection{Motor Supported by Periodic Mounts}

Figures 11 - 13 display the magnitude of the transfer function between the input excitation of the motor and the transmitted acceleration to the base as obtained by a passive mount with geometrical and material discontinuities. It is evident that the passive mounts have been effective in attenuating the vibration transmission from the motor to the base. However, it is important to note that the use of mounts with material discontinuities is found to be more effective in suppressing the vibration transmission than the mounts with geometrical discontinuities. Such effectiveness stems from the fact that material discontinuities result in higher impedance mismatch at the discontinuity interfaces. 

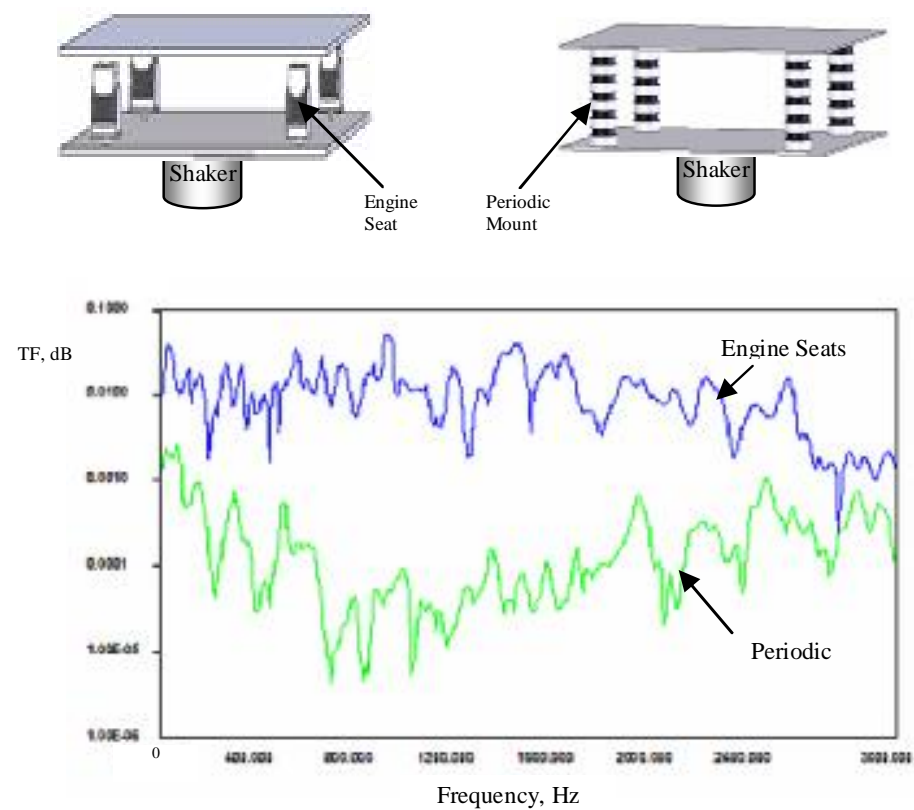

Fig. 11. Vibration transmission from the shaker through the engine seats and periodic mounts to the upper plate.
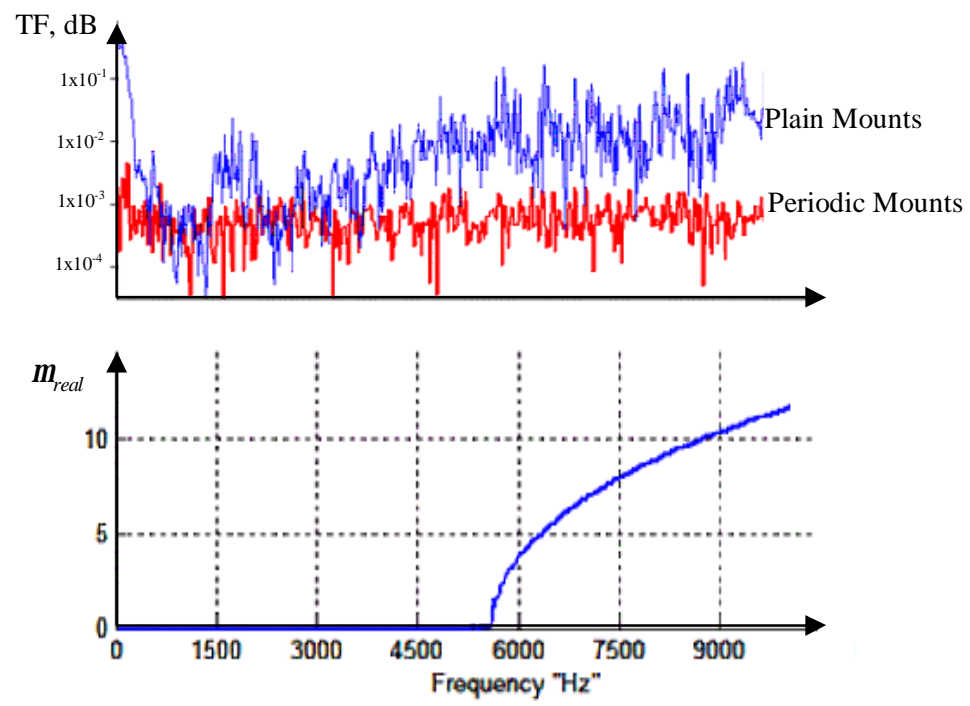

Fig. 12. Vibration transmission from motor supported by periodic mounts with geometrical periodicity ( $D_{a}=5 \mathrm{~mm}, L_{a}=50 \mathrm{~mm}, D_{b}=50 \mathrm{~mm}$, and $\left.L_{b}=24 \mathrm{~mm}\right)$. 

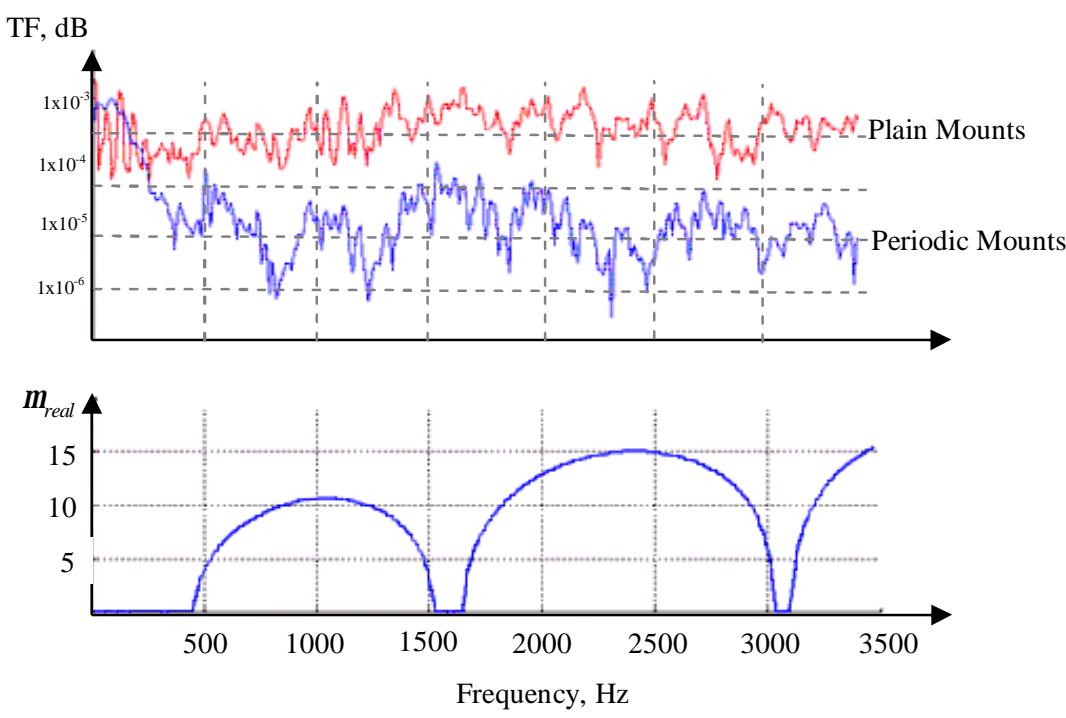

Fig. 13. Vibration transmission from the motor through the periodic mounts (five cells) with geometrical and material periodicity $\left(D_{a}\right.$ (Aluminum) $=50 \mathrm{~mm}, \mathbf{L}_{\mathbf{a}}=\mathbf{2 0} \mathrm{mm}$, $D_{b}($ Rubber $)=43 \mathrm{~mm}$, and $\left.\mathrm{L}_{\mathbf{b}}=15 \mathrm{~mm}\right)$.

\section{Conclusions}

This paper has presented a new class of periodic mounts for isolating the vibration transmission from vehicle engine to the car body and seats in an attempt to produce quiet interior environment of the vehicle. The theory governing the operation of this class of mounts has been presented. The factors governing the design of effective mounts have been identified. The performance characteristics of passive mounts alone have been measured experimentally and compared with the theoretical predictions. Close agreement between theoretical predictions and experimental results has been achieved. The performance of the mount with a motor assembly has also been monitored experimentally. The predictions of the stop bands have also been found to be in close agreement with the experimental results. The periodic mounts have been compared to plain mounts. Such periodic mounts are found to be much more effective than the engine seats in attenuating the transmission of vibrations. Mounts with geometrical and material discontinuities are found to be more effective in attenuating the transmission of vibration from the motor to the body. Such effectiveness is attributed to the large 
degree of impedance mismatch produced with geometrical and material discontinuities.

Attempts to provide the passive mounts with active control capabilities are a natural extension of the present study. Apart from their unique filtering characteristics, the ability of periodic mounts to transmit waves, from one location to another, within the pass bands can be greatly reduced when the ideal periodicity is disrupted or disordered. Attempts will be made to capitalize on such unique characteristics. This results in the well-known phenomenon of "Localization" whereby the effects of an external disturbance are localized at (or confined to) the structural zone surrounding it ${ }^{[17]}$. In the case of passive mounts, the aperiodicity (or the disorder) can result from unintentional material, geometric and manufacturing variability. However, in the case of active periodic mounts the aperiodicity can be intentionally introduced by proper tuning of the controllers of the individual substructure or cell ${ }^{[18]}$ Baz and Asiri et. $a l^{[15]}$. With such unique filtering/localization characteristics of the periodic/aperiodic mounts, it would be possible to passively or actively control the wave propagation both in the spectral/spatial domains in an attempt to stop/confine the propagation of undesirable disturbances.

\section{References}

[1] Brillouin, L., Wave propagation in periodic structures, $2^{\text {nd }}$ ed., Dover, (1946).

[2] Mead, D. J., Free Wave Propagation in Periodically Supported, Infinite Beams, Journal of Sound and Vibration, 11: 181-197, (1970).

[3] Cremer, L., Heckel, M. and Ungar, E., Structure-Borne Sound, Springer-Verlag, New York, (1973).

[4] Faulkner, M. and Hong. D., Free Vibration of a Mono-Coupled Periodic System, Journal of Sound and Vibrations, 99:29-42, (1985).

[5] Mead, D. J., Vibration response and wave propagation in periodic structures, Journal of Engineering for Industry, 21: 783-792, (1971)

[6] Mead, D. J., Wave propagation and natural modes in periodic systems: I. Mono-coupled systems, Journal of Sound and Vibration, 40; 1-18(1975).

[7] Mead, D. J., A New Method of Analyzing Wave Propagation in Periodic Structures; Applications to Periodic Timoshenko Beams and Stiffened Plates", Journal of Sound and Vibration, 114: 9-27 (1986).

[8] Gupta, S., Periodically-Supported Beams and Plates", Journal of Sound and Vibration, 13: 89-111 (1971).

[9] Richards D and Pines D J., Passive Reduction of Gear Mesh Vibration Using a Periodic Drive Shaft, Journal of Sound and Vibration, 264: 2 (2003).

[10] Asiri, S., Tunable Mechanical Filter for Wave Propagation of Longitudinal Vibrations, International Journal of Acoustics and Vibrations, In press (2005)

[11] Asiri, S., Baz, A. and Pines, D., Periodic Struts for Gearbox Support System, Proc. Of the 2002 International Congress and Exposition on Noise Control Engineering, Inter Noise 2002, Paper number IN02-644, Dearborn, MI, USA. August 19-21 (2002). 
[12] Sackman, S., Kelly, J. and Javid, A. A., Layered Notch Filter for High-Frequency Dynamic Isolation, Journal of Pressure Vessel Technology, 111: 17-24(1999).

[13] Szefi, J. T., Smith, E. C. and Lesieutre, G. A., Analysis and Design of High Frequency Periodically Layered Isolators in Compression, $41^{\text {st }}$ Structures, Structural Dynamics and Materials Conference, Atlanta, GA (2002).

[14] Baz, A., "Active control of periodic structures", ASME Journal of Vibration and Acoustics, 123; $472-479$ (2001).

[15] Asiri, S., Baz, A. and Pines, D., Active Periodic Struts for Gearbox support System, Proc. of SPIE, Smart Structures and Materials 2004: Damping and Isolation, 5386; $347-358$ (2004).

[16] Doyle, J., Wave Propagation in Structures, $2^{\text {nd }}$ ed., Springer-Verlag, New York (1997).

[17] Pierre, C., Mode Localization and Eigenvalue Loci Veering Phenomena in Disordered Structures, Journal of Sound and Vibration, 126: 485-502 (1988).

[18] Baz, A., Spectral Finite Element Modeling of Longitudinal Wave Propagation in Rods with Active Constrained Layer Damping, Smart Materials and Structures, 9; 3, 372-377 (2000). 
قو ائم التثبيت الدورية لعزل اهتزازت محرك العربة المتحركة

$$
\text { سعيد عسيري، وعبدالغفار أزهري الجاوي }
$$

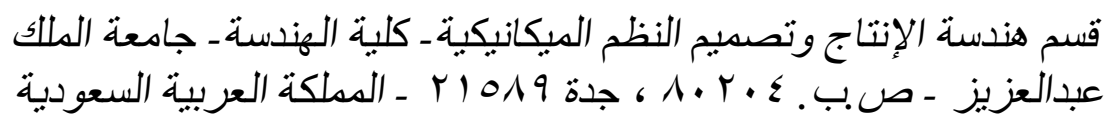

المستخلص . في هذه الورقة نم تقديم نوع جديد من قوائم التنبيت

الدورية لعزل انتقال الاهتزاز من محرك العربة إلى جسم السيارة

وكذلك مقاعد العربة. هذا النوع من قوائم النتييت نظهر فيه

خصائص ديناميكية فريدة حيث تقوم بدور المرشح الميكانيكي

لسريان الموجات. ونتيجة لذلك فإن الموجات نتفذ خلاد القائم

الدوري فقط إذا كان التردد الموجي للموجات في نطاقات ترددي

معين بسمى :"نطاق النفوذ" وفي المقابل فإنها تعزل الموجات

بالكامل إذا كان التزدد في نطاق ترددي معين يسمى: "تطاق

وقد نم إجر اء التجارب المعطلة، أولا بما في ذلك تصميم

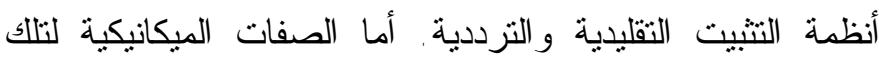
الأنظمة فقد تم الحصول عليها معمليا في كلتا الحالتين. وبعد ذللك، تم إجر اء التجارب لدراسة خصائص أداء القوائم التنييتية الدورية نتيجة لتغير الثنكل الهندسي و /أو نوع المادة لها. كما تم أيضا إثبات جدوى الدورية على مستويات الاهنز از لأنظمة قو ائم التثبيت

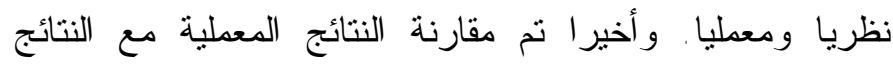
النظرية وكان هناك تو افق بين النظرية و التجارب . 